\title{
Correlation of clinical, biochemical and functional parameters with histological lesions in secondary renal amyloidosis
}

\author{
P. D. Gulati \\ M.D. \\ Assistant Professor of Medicine \\ G. P. Mathur \\ M.Sc. \\ Statistician, New Delhi \\ Tuberculosis Centre
}

\author{
A. L. Aurora \\ M.D., Ph.D. \\ Assistant Professor of Pathology \\ H. VAIShNAVA \\ F.R.C.P.E. \\ Professor of Medicine
}

The Renal Unit, Department of Medicine,
Maulana Azad Medical College,
New Delhi, India

\section{Summary}

The records of fifty-five patients with secondary renal amyloidosis have been scrutinized in order to evaluate statistically the correlation of the various clinical features and biochemical alterations with the severity of histological lesions in this disease. An 'amyloid factor', calculated on the basis of the extent of glomerular amyloid deposition, was utilized for the grading of the latter.

A significant correlation of the histological grading was observed with the duration of predisposing illness $(P<0.02)$, alteration of total serum protein $(P<0.001)$ and functional impairment as determined by the creatinine clearance test $(P<0.002)$. There was, however, no significant correlation between the extent of glomerular lesions and clinical severity, the duration of oedema, the degree of proteinuria and the levels of blood urea, serum albumin and serum cholesterol.

\section{Introduction}

Since the introduction of renal biopsy, several studies have been carried out in Western countries in order to find out the clinico-pathological correlations in renal diseases (Hutt, Pinniger \& de Wardener, 1958; Parish et al., 1961; Bergstrand \& Bucht, 1961). Most of these have been done in glomerulonephritis and comparatively few in renal amyloidosis, although the disease is not uncommon in India as well as in the West (Briggs, 1961; Vaishnava, Gulati \& Aurora, 1969). However, in recent years, a few reports indicating divergent views on the correlation of glomerular changes with functional alterations in amyloid disease of the kidney have appeared in the literature (Bell, 1950; Heptinstall \& Joekes, 1960; Bergstrand \& Bucht, 1961).

Of late, renal amyloidosis has assumed much greater clinical significance, because it has been recognized to be the commonest underlying cause of the nephrotic syndrome in adults in this part of the world (Sarin \& Sarin, 1960; Vaishnava et al., 1969). Renal manifestations of amyloidosis are protean, as revealed by the clinical picture and also by the results of laboratory investigations. The diagnosis is, however, made with great certainty by needle biopsy of the kidney. But the value of this procedure as a guide to the severity of the clinical, biochemical and renal functional changes induced by amyloidosis, has not been properly evaluated so far. It is for this reason that correlative studies based on multifactorial statistical analysis were considered essential.

The present communication aims at correlating some of the features such as the clinical severity judged from the extent of oedema and ascites, the duration of symptoms, changes in blood pressure, the duration of the known predisposing illness, the degree of proteinuria, abnormalities of serum proteins and cholesterol and functional impairment as determined by levels of blood urea and creatinine clearance, with the histological lesions seen in renal amyloidosis.

\section{Materials and methods}

The data for this report has been collected from a prospective study of seventy-eight cases of renal 
amyloidosis, studied in the Renal Unit of the Maulana Azad Medical College and Associated Hospitals, New Delhi, India, over a period of 5 years. Records of fifty-five patients only, in whom fresh sections were available, were utilized for the purpose of statistical evaluation. The diagnosis of renal amyloidosis was confirmed by needle biopsy/ autopsy in all patients.

All the patients were examined and investigated soon after admission and before any treatment was instituted. They were carefully interrogated for the duration of presenting symptoms and the predisposing diseases. In each patient the clinical severity was arbitrarily graded as,+++ or +++ on the basis of the extent of fluid retention, i.e. + when puffiness of face was noticed with or without ankle oedema; ++ when oedema extended to the legs and sacrum; and +++ when generalized anasarca was present along with evidence of fluid in the peritoneal and/or pleural cavities.

Daily excretion of urinary proteins was estimated in every patient by the turbidimetric method (King, 1964). Biochemical tests included the determination of plasma proteins, serum albumin, serum cholesterol and blood urea by the standard techniques (King, 1964). The creatinine clearance was estimated in forty-one cases.

Fresh microscopic sections of kidney tissue, obtained from the biopsy or autopsy material, were stained with $\mathrm{H} \& \mathrm{E}$ which showed hyaline widening of the inter-capillary regions on light microscopy. In order to confirm that these hyaline deposits were due to accumulation of 'amyloid' and not other proteinaceous substances, methyl violet was used and unmounted preparations immediately examined under the low power $(\times 100)$. The extent of the amyloid deposit in the glomeruli was divided into three categories depending upon the involvement of a quarter, a half, three-quarters, or the whole of the glomerulus in serial sections. From the extent and intensity of deposits and the number of glomeruli, an 'amyloid factor' was determined in each case. For example, if there were twenty glomeruli, of which thirteen showed + involvement (one-quarter of each glomerulus) and the other seven ++ involvement (one-half of each glomerulus), the factor was calculated as follows:

$$
\left(\frac{1}{4} \times 1 \times 13\right)+\left(\frac{1}{2} \times 2 \times 7\right) / 20=0.513 .
$$

The severity of amyloid deposits, calculated above as 'amyloid factor' was correlated with the duration of predisposing illness, clinical severity, duration of oedema, degree of proteinuria and biochemical and functional abnormalities as indicated above. A statistical evaluation of these relationships has also been carried out.
Results

\section{Baseline studies}

Clinical severity. According to the clinical criteria described earlier, there were fifteen patients with mild $(+)$, eighteen with moderate $(++)$ and twenty-two with severe disease $(+++)$. The duration of oedema ranged from 10 days to $1 \frac{1}{2}$ years, mean being $4.5 \pm 1.95$ months. High blood pressure (over $150 / 90 \mathrm{mmHg}$ ) was seen in five patients, four of whom were uraemic; two had lesions suggestive of chronic pyelonephritis on renal biopsy. The predisposing illness was pulmonary tuberculosis in forty-six cases, bronchiectasis in three, tuberculous lymphadenopathy in three, rheumatoid arthritis in two and lepromatous leprosy in one. The duration of the predisposing illness prior to the development of oedema was known in forty-nine patients. It ranged from 5 months to 7 years, and was less than 1 year in thirteen and 1 year or more in the remaining forty-two patients.

Severity of proteinuria. Daily protein excretion ranged from 3.2 to $12.6 \mathrm{~g} / 24 \mathrm{hr}$ (mean $7 \cdot 2 \pm 2 \cdot 1 \mathrm{~g}$ / $24 \mathrm{hr}$ ). It was less than $5 \mathrm{~g} / 24 \mathrm{hr}$ in nineteen and $5 \mathrm{~g}$ or more in the remaining thirty-six patients.

Biochemical abnormalities. Serum proteins were less than $5 \mathrm{~g} / 100 \mathrm{ml}$ in forty-seven patients (mean $4.8 \pm 1.4 \mathrm{~g} / 100 \mathrm{ml}$ ). Serum albumin was less than $2.5 \mathrm{~g} / 100 \mathrm{ml}$ in all (mean $1.9 \pm 0.75 \mathrm{~g} / 100 \mathrm{ml}$ ). Levels of serum cholesterol were over $200 \mathrm{mg} / 100 \mathrm{ml}$ in thirty-three patients, range being $156-605 \mathrm{mg} / 100 \mathrm{ml}$ (mean $256 \pm 68.5 \mathrm{mg} / 100 \mathrm{ml}$ ).

Functional derangement. This was assessed by the estimation of blood urea in all and creatinine clearance in forty-one patients. Blood urea levels ranged from 24 to $197 \mathrm{mg} / 100 \mathrm{ml}$; it was over $60 \mathrm{mg} / 100 \mathrm{ml}$ in twenty-three patients, all of whom died. The creatinine clearance ranged from 25.4 to $68.5 \mathrm{ml} / \mathrm{min}$ (mean $58.5 \pm 13.0 \mathrm{ml} / \mathrm{min}$ ), a clearance rate of less than $60 \mathrm{ml} / \mathrm{min}$ was found in thirty patients.

Severity of histological lesions. Based on the calculation of the 'amyloid factor' as indicated earlier, the severity of the lesions was graded as I, if the factor value was less than 1 ; II if between 1 and 2; and III if it was over 2 . Thus in the fifty-five specimens examined the lesions were grade I in eleven; grade II in nineteen; and grade III in twenty-five cases. Lesions of chronic pyelonephritis were observed in five specimens.

\section{Correlative studies}

Clinical severity and duration of predisposing illness. The clinical severity of the disease and the duration of the predisposing illness did not have any correlation (Table 1). 
TABLE 1. Correlation of clinical severity with the duration of predisposing illness

\begin{tabular}{cccc}
\hline Clinical severity & $\begin{array}{c}1 \text { year } \\
(13)\end{array}$ & $\begin{array}{c}1-2 \text { years } \\
(37)\end{array}$ & $\begin{array}{c}>2 \text { years } \\
(5)\end{array}$ \\
\hline+ (mild) $(15)$ & 4 & 9 & 2 \\
++ (moderate) $(18)$ & 5 & 13 & 0 \\
$+++($ severe $)(22)$ & 4 & 15 & 3 \\
\hline
\end{tabular}

Clinical severity and grade of histological lesions. No correlation was observed between the clinical severity and the grade of morphological lesions of the disease (Table 2).

TABLE 2. Correlation of clinical severity and grade of histological lesions

\begin{tabular}{lccc}
\hline & \multicolumn{3}{c}{ Clinical severity } \\
\cline { 2 - 4 } Histological & $\begin{array}{l}\text { Mild } \\
\text { grading }\end{array}$ & $\begin{array}{c}\text { Moderate } \\
(18)\end{array}$ & $\begin{array}{c}\text { Severe } \\
(22)\end{array}$ \\
\hline Grade I (11) & 3 & 4 & 4 \\
Grade II (19) & 4 & 7 & 8 \\
Grade III (25) & 8 & 7 & 10 \\
\hline
\end{tabular}

Duration of symptoms and grade of histological lesions. There was no apparent correlation between the clinical severity and the duration of symptoms. One might expect that, being a long-standing disease, a correlation might exist between the duration of symptoms and the histological severity but on statistical analysis there was no significant correlation between these two factors (Table 3).

TABLE 3. Correlation of duration of symptoms with the grade of histological lesions

\begin{tabular}{lccc}
\hline $\begin{array}{l}\text { Histological } \\
\text { grade }\end{array}$ & $\begin{array}{c}\text { Up to 3 } \\
\text { months }\end{array}$ & $\begin{array}{c}3 \cdot 1-6 \\
\text { months }\end{array}$ & $\begin{array}{c}\text { More than 6 } \\
\text { months }\end{array}$ \\
\hline I (11) & 2 & 3 & 6 \\
II (19) & 8 & 6 & 5 \\
III (25) & 5 & 11 & 9 \\
\hline
\end{tabular}

Statistical evaluation $P>0 \cdot 10$ (not significant)

Duration of predisposing illness and grade of histological lesions. This correlation was possible in forty-nine out of fifty-five cases, as the predisposing illness in the remaining six patients was detected only on routine examination and by roentgenography. Apparently, as the duration of symptoms of the predisposing illness increased, the value of the amyloid factor also increased. This was further supported by the statistical analysis which revealed significant correlation $(P>0.02)$, (Fig. 1).

Degree of proteinuria and grade of histological lesions. Statistically, there was no significant correlation between the daily excretion of protein and

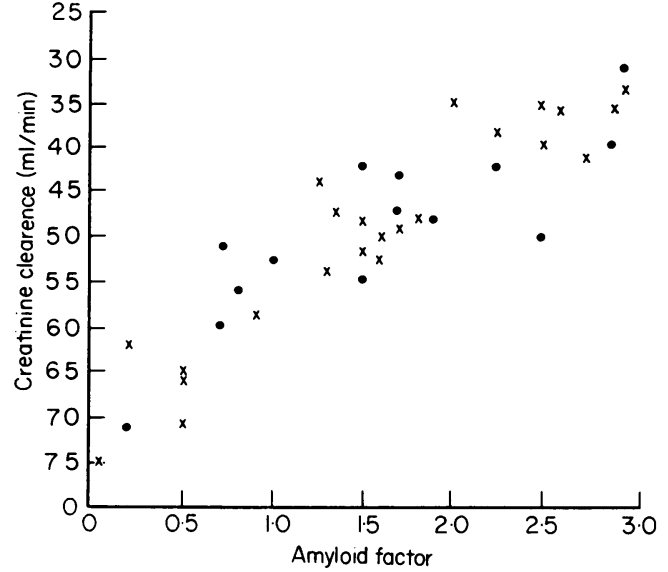

Fig. 1. Scatter-diagram showing a significant correlation of the duration of predisposing illness and the intensity of amyloid deposition $(P<0.02) . \times$, Biopsyproven cases; $\boldsymbol{O}$, autopsy-proven cases.

TABLE 4. Correlation of proteinuria with the grade of histological lesions

\begin{tabular}{lccc}
\hline & \multicolumn{3}{c}{ Proteinuria (24 hr) } \\
\cline { 2 - 4 } $\begin{array}{l}\text { Histological } \\
\text { grade }\end{array}$ & $\begin{array}{c}<\mathrm{g} \\
(19)\end{array}$ & $5-8 \mathrm{~g}$ & $\mathbf{8} \mathrm{g}$ \\
\hline I (11) & 3 & 4 & $(11)$ \\
II (19) & 8 & 8 & 4 \\
III (25) & 8 & 13 & 4 \\
\hline
\end{tabular}

Statistical evaluation $P>0 \cdot 10$ (not significant)

the severity of histological change $(P>0 \cdot 10)$ (Table 4).

Biochemical abnormalities and grade of histological lesions. The correlation between the level of serum protein and the extent of the lesion was statistically significant $(P<0.001)$ (Fig. 2) but no significant correlation was observed between serum albumin abnormalities and the severity of amyloid deposits $(P>0 \cdot 10)$. Hypercholesterolaemia was observed in thirty-five patients but its correlation with the renal deposits of amyloid was not significant $(P>0 \cdot 10)$.

Functional derangement and grade of histological lesions. Blood urea levels were elevated in thirteen cases but the rise was not significantly related to the extent of the amyloid lesions $(P>0 \cdot 10)$. On the other hand, the creatinine clearance showed a statistically significant correlation with the glomerular changes $(P>0.002)$ (Fig. 3).

Grade of histological lesion and ultimate outcome. Out of fifty-five patients, twenty-three died during the hospitalization period (11-29 weeks). The histological lesion was grade I in five, grade II in six and grade III in twelve cases. Death was preceded by an episode of diarrhoea in seven cases. 


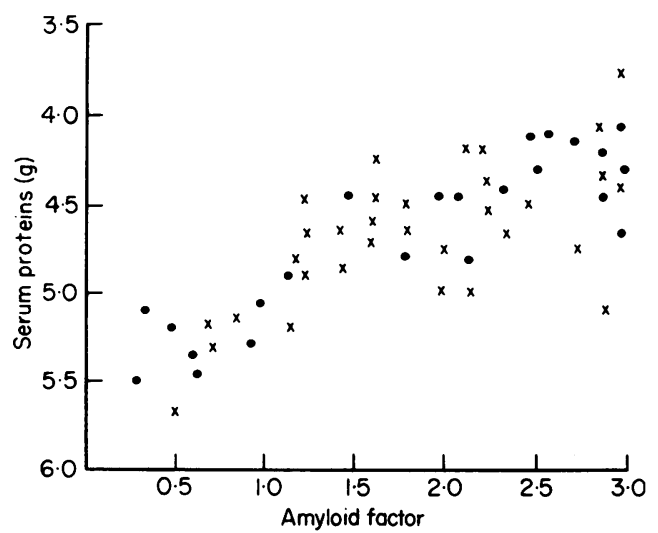

FIG. 2. Scatter-diagram showing a significant correlation of the serum protein abnormality with the intensity of amyloid deposition $(P<0.001)$. Key as Fig. 1 .

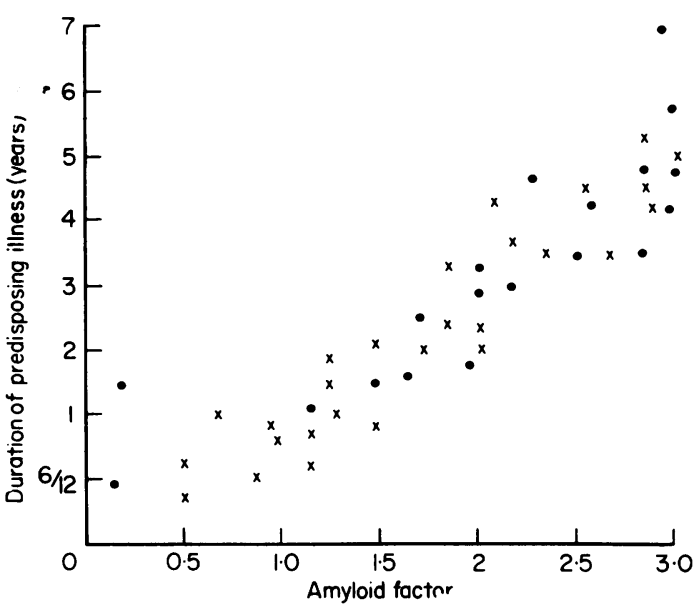

Fig. 3. Scatter-diagram showing a significant correlation of the values of creatinine clearance with the intensity of amyloid deposition $(P<0.002)$. Key as Fig. 1.

\section{Discussion and conclusions}

It is well known that amyloid deposition in the kidney provides the first and sometimes the sole clue to the presence of this disorder in the body. The severity of the clinical manifestations of renal amyloidosis may be related to the extent of renal deposition of amyloid as well as to its duration. But it is evident from Table 2 that no significant correlation existed between them. An illness of shorter duration often presented a fulminating clinical picture whereas patients with a long-standing illness at times presented with only slight or no oedema. Moreover, the grades of clinical severity did not show any relationship with the extent of amyloid changes in the glomeruli. Hutt et al. (1958) and Jennings \& Earle (1961) also made similar observations in their patients with glomerulonephritis associated with the nephrotic syndrome. The reports of asymptomatic cases of renal amyloidosis, detected at necropsy, similarly provided support to this finding (Aurbach \& Stammerman, 1944).

Bell (1950) suggested that the degree of hypertension in renal amyloidosis could be correlated with the extent of amyloid involvement of the kidney. This, however, was not borne out by the present study. In general, the prevalence of hypertension is believed to be either lower than or comparable with that of the normal population in different age-groups (Dahlin, 1949; Zuckerbrod, Rosenberg \& Keyden, 1956; Vaishnava et al., 1969). Raised blood pressure, whenever present, was associated with concomitant renal insuffic:ency and changes of chronic pyelonephritis were seen on renal biopsy in two out of six hypertensive patients.

It is noteworthy that the extent of amyloid deposition in the kidney was significantly correlated with the duration of the existence of the known predisposing illness $(P<0.002)$. This fact has not been brought out in the earlier reports (Dahlin, 1949; Briggs, 1961). It signifies the importance of the early detection of amyloid disease in patients with tuberculosis and other well recognized predisposing illnesses. Effective therapy of the latter at this stage might, therefore, prevent the progression of amyloidosis. However, in a few cases, the predisposing illness was of comparatively short duration and was occasionally detected only after the renal biopsy had shown amyloidosis.

Proteinuria of varying degree in the presence of known predisposing illness provides the most important diagnostic clue. Nevertheless, the present study did not show any significant relationship of this protein loss to the extent of glomerular involvement by the amyloid process. Maximum daily protein leakages of $12.6 \mathrm{~g}$ occurred with only grade II lesions; whereas minimal proteinuria was observed in cases having grade III deposits. Besides, intermittent albuminuria was observed with a severe degree of amyloid deposition. Almost similar findings, although based on a smaller number of cases, were also recorded by Heptinstall \& Joekes (1960) in renal amyloidosis, and by Berman \& Voglestrong (1963) and Cohen \& Levitt (1963), in cases of glomerulonephritis.

The nephrotic syndrome characterized by massive oedema, gross proteinuria and hypoproteinaemia was the commonest mode of presentation in our cases of renal amyloidosis. In spite of the absence of a significant relationship between the degree of proteinuria and the grade of amyloid factor the latter was significantly correlated with the abnormalities of serum proteins $(P<0.001)$. 
In recent years, certain workers have commented on the well-preserved renal function in the presence of marked glomerular changes in amyloidosis (Bergstrand \& Bucht, 1961). In the present study, although there was no significant correlation of blood urea levels with the intensity of amyloid deposition in the glomeruli, yet when the latter was correlated with the endogenous creatinine clearance, a statistically significant correlation emerged $(P<0.002)$. Bell $(1950)$ also suggested that renal insufficiency, indicated by glomerular filtration rate, was directly proportional to the changes in the glomeruli.

An attempt was also made to study the correlation of the histological lesions with the ultimate clinical course. Half the patients who died of renal failure during their stay in the hospital showed a severe grade of amyloid change (grade III), but the remaining half showing only grade I or grade II change, also died. The reason for this observation is not very clear. Death in the latter was usually precipitated by an episode of intercurrent infection, mostly of the gastrointestinal tract. This obviously resulted in a state of fluid and electrolyte imbalance which might have been partly responsible for death in patients with less-marked amyloid deposits. However, in a few patients, a refractory predisposing illness contributed.

\section{Acknowledgments}

Our thanks are due to Dr N. Arora, Dr N. S. Dixit, Dr G. Natarajan and many house-physicians of our unit, who helped in the collection and analysis of the data.

\section{References}

Auerbach, O. \& Stammerman, M.I. (1944) Renal amyloidosis. Archives of Internal Medicine, 74, 244.
Bell, E.T. (1950) Renal Disease, 2nd edn. Lea \& Febiger, Philadelphia.

Berman, L.B. \& Vogelstrong, P. (1963) Post-streptococcal glomerulonephritis without proteinuria. New England Journal of Medicine, 28, 1275.

Bergstrand, A. \& Bucht, H. (1961) Electron microscopy and renal function in amyloidosis of kidney. Journal of Pathology and Bacteriology, 82, 495.

Briggs, G.W. (1961) Amyloidosis. Annals of Internal Medicine, 55, 943.

Cohen, J.A. \& LevitT, M.L. (1963) Acute glomerulonephritis with few urinary abnormalities: Report of two cases proven by renal biopsy. New England Journal of Medicine, 268, 749.

DAhlin, D.C. (1949) Secondary amyloidosis. Annals of Internal Medicine, 31, 105.

Heptinstall, R.H. \& Joekes, A.M. (1960) Renal amyloidosis-A report of 11 cases proven by renal biopsy. Annals of the Rheumatic Diseases, 19, 126.

Hutt, M.S.R., Pinniger, J.L. \& DE WARdener, H.W. (1958) The relationship between clinical and the histological factors in acute glomerulonephritis: based on a study of renal biopsy material. Quarterly Journal of Medicine, 27, 265.

Jennings, R.B. \& Earle, D.P. (1961 Post-streptococeal glomerulonephritis: histologic and clinical study of the acute, subsiding acute and the early chronic latent phases. Journal of Clinical Investigation, 40, 1525.

KING, E.J. (1964) Micro-Analysis in Medical Biochemistry. Churchill, London.

Parish, A.E., Krammer, N.C., Hatch, F.E., Watt, M.F. \& HAVER, J.C. (1961) The relation between glomerular function and histology in acute glomerulonephritis. Journal of Laboratory and Clinical Medicine, 58, 197.

SARIN, L.R. \& SARIN, J.C. (1960) Nephrotic syndromeA clinico-pathological study of 50 cases in adults. Journal of the Association of Physicians of India, 13, 761.

Vaishnava, H., Gulati, P.D. \& Aurora, A.L. (1969) A clinico-pathological study of renal amyloidosis in Northern India. (In press).

ZuCkerbrod, M., Rosenberg, B. \& Keyden, H.J. (1956) Renal insufficiency and hypertension associated with secondary amyloidosis. American Journal of Medicine, 21, 227. 